Stoa

Vol. 4, no. 8, 2013, pp. 47-74

ISSN 2007-1868

\title{
LA HERMENÉUTICA ANALÓGICA COMO TEORÍA DE LA ACCIÓN HUMANA*
}

\author{
Julio Quesada Martín \\ Instituto de Filosofía \\ Universidad Veracruzana \\ quesadajulio@yahoo.es
}

RESUMEN: En este texto, se expone una comprensión del trabajo de Mauricio Bechot, Tratado de Hermenéutica, en el que, contrastándolo con el trabajo y pensamiento de Heidegger, brinda una aproximación a lo que se conoce como Analogía Hermenéutica. Con esto, se muestra lo evidente de los alcances de la conciencia filosófica liberal humanista y que a su vez han desintegrado diversos cortes antifilosóficos gestados en el siglo xx. Nociones de identidad e interpretación del otro como paradigma de interconexiones para construir nuestra propia cultura. También se evidencian las faltas o errores en la interpretación de la obra de Heidegger por diferentes autores, que lo asumieron como deconstructor siendo en realidad un destructor. Finalmente, se presenta a la Hermenéutica Analógica como un nuevo panorama de pensamiento en el que tiene como cimientos a la verdad, la libertad y la felicidad, para demostrar que el mundo sí tiene sentido.

PAlABRAS ClAVE: Heidegger - Mauricio Beuchot · Vattimo - Hermenéutica Analógica $\cdot$ vida $\cdot$ humano $\cdot \operatorname{modernidad} \cdot$ identidad

ABSTRACT: This essay exposes a grasp of Mauricio Bechot's Tratado de Hermenéutica where opposing it with Heiddeger's work and thought, provides an approach to what is known as Analogía Hermenéutica. The purpouse is to show how evident the ranges of the phylosophical humanist liberal conscience are and how they have desintegrated many antiphylosophycal humanist cuts gestated in the 20 th century. Identity and interpretation notions of the

\footnotetext{
* Ponencia presentada en el Coloquio sobre Hermenéutica analógica, celebradao en la
} UNAM-Instituto de Filllológicas, México, el 16 de octubre 2012. 
other one as an interconection's paradigm to construct our own culture. As well, it evinces mistakes by many authors in the interpretation of Heiddeger's work, who assumed him as a deconstructor instead of a destroyer. Finally, Hermenéutica Analógica is presented as a new pesrpective wich has as foundations the truth, freedom and hapiness to prove that the world has a meaning indeed.

KEYwords: Heidegger - Mauricio Beuchot - Vattimo - Analogic Hermeneutic · Life $\cdot$ Human $\cdot$ Modernity $\cdot$ Identity

\section{Introducción}

Voy a tratar en estas breves reflexiones de tematizar los presupuestos ontológicos, éticos, políticos y estéticos de la Hermenéutica analógica. No me interesa hacer aquí un ejercicio académico de halterofilia de citas, sino un ensayo. Intento entrar en diálogo con el meollo de la Hermenéutica analógica desde mis propios horizontes de lectura.

Nuestra hipótesis de trabajo considera que el Tratado de Hermeneútica analógica del mexicano Mauricio Beuchot se comprende mejor al trasluz de la hermenéutica de la facticidad histórica de Martín Heidegger o Indicación de la situación hermenéutica, subtítulo dado por Heidegger a Interpretaciones fenomenológicas sobre Aristóteles [Informe Natorp] de 1922, auténtico "laboratorio" de Sein und Zeit (1927). Desde mi punto de vista (y señalando que metodológicamente me centro en los dos primeros capítulos del Tratado en donde el propio Beuchot define y desarrolla, al menos en parte, sus principios hermenéuticos de base, esto es, su propia indicación de la situación hermenéutica de la Hermenéutica analógica), lo que separa de forma irreductible (sin posibilidad de analogía) la ontología de Heidegger de la de Beuchot tiene, como mínimo, estas clave: 1) finitud; 2) historicidad (o reducción de "pueblo" a "pueblo histórico"); 3) comunidad del Volk (pueblo alemán); 4) destino y destino común (Gemainschaft): 5) ser para la muerte como ofrenda del Dasein al Volk en su cierre y sello (Prägung) sobre sí mismo y, como consecuencia de todo lo anterior, 6) una concepción existenciaria del espíritu y de la ciencia (auténticamente alemana) que hace de la Sorge o cuidado del Dasein en su Volk un cordón sanitario que divide, rompe, el continuum de la vida, de la existencia y de la historia en "propios" vs "impropios", "auténticos" vs "inauténticos" y como funda- 
mento de "La tarea de una destrucción de la historia de la ontología" (Heidegger, 2003).

Teniendo en cuenta las extraordinarias investigaciones contemporáneas llevadas a cabo por Roberto Esposito en Bíos. Biopolítica y filosofía, me considero con bastante derecho a bautizar la hermenéutica heideggeriana con el título de "Hermenéutica inmunológica" porque esta vuelta al origen, hija, a su vez, del espíritu de su época, esta vuelta al origen (Ursprung] del Dasein $=$ Volk $^{1}$ a tan sólo seis años de que los nazis tomen democráticamente el poder para exigir que los alemanes demuestren, mediante certificados de nacimiento de sus cuatro abuelos, que son realmente arios, esta hermenéutica de la Existenz frente a la inautenticidad de la existentia democrática, ya en clave de Das Man o $S e$ (el Uno), bien en clave platónica anti-sofista y anti-ilustrada de la doxa u opinión pública que debe ser expulsada de la comunidad y, de ahí, que la función primordial del Reich o Estado consista para Heidegger como para el antisemita conde Paul de Yorck von Wartenburg con quien el filósofo comparte estas ideas en el $\$ 77$ de Sein und Zeit, esta hermenéutica de la verdadera existencia o del verdadero Ser, decíamos, encierra un choque de civilizaciones en el mismísimo corazón de Europa y cuyo resultado no podía ser otro, dadas las circunstancias históricas adecuadas, que el holocausto de los judíos así como la purga y aniquilación de las demás existencias inauténticas, impropias, respecto del Ser.

Ante esta vida del siglo xx tan dañada, que dijo Adorno, ¿qué podemos hacer? Lo que el espíritu de la hermenéutica analógica propone como un deber hermenéutico (Aristóteles-Kant) es el de "respetar al autor". Pero no en el sentido en que toman los heideggerianos precríticos a su vaca sagrada: un objeto de culto eximido de la crítica; ${ }^{2}$ sino

\footnotetext{
${ }^{1}$ Las lecturas que se han hecho de Sein und Zeit tomando como centro de gravedad de la ontología heideggeriana el hipotético "individuo" auténtico que debería latir en el Dasein, estas lecturas idealizan un error de interpretación ya que para Heidegger la auténtica subjetividad sólo la da el pueblo o Volk (Ser y tiempo, \$77 y 74). De ahí que vengamos insistiendo en que debemos comenzar la lectura de la obra de Heidegger desde el final, desde la historicidad del Dasein que sólo le viene dado en calidad de "comunidad" y nunca jamás a efectos modernos de algún tipo de subjetividad personal o individual.

2 "La razón pura tiene que someterse a la crítica en todas sus empresas. No puede oponerse a la libertad de esa crítica sin perjudicarse y sin despertar una sospecha que le es desfavorable. Nada hay tan importante, desde el punto de vista de su utilidad, nada tan sagrado, que pueda eximirse de esta investigación comprobadora e inspección, de una investigación que
} 
en el respeto que se le tiene a la otra persona cuando nos citamos con ella para intercambiar ideas y, tal vez, afectos o desacuerdos pero sin franquea esa delgada línea roja que nos llevaría no sólo a la destrucción de la intencionalidad de la conciencia del otro sino a asesinarlo porque no piensa como nosotros o no es como nosotros.

\section{La hermenéutica heideggeriana como "hermenéutica inmuninológica"}

En el $§ 35$ de Kant y el problema de la metafísica $(K M, 1929)$ así explicó Heidegger en qué consistía la exégesis de un texto:

Es cierto que toda interpretación, para extraer de las palabras todo lo que éstas quieren decir, debe recurrir necesariamente a la fuerza $[K r a f t]$. Pero esta fuerza no puede ser un vago capricho. La exégesis debe estar animada y conducida por la fuerza de una idea inspiradora. Únicamente esta fuerza permite que una interpretación se atreva a emprender lo que siempre será una audacia, es decir, confiarse a la secreta pasión de una obra, para penetrar, por su medio, hasta lo que quedó sin decir, y tratar de expresarlo. He aquí un camino para que la idea directora misma aparezca en su propia fuerza esclarecedora (1973, p. 170).

La hermenéutica de la facticidad histórica del Dasein en su Volk-\$74 de Ser y tiempo- se revela como el cierre ontológico y político del pensamiento heideggriano contra el principio excéntrico de la modernidad filosófica, científica y política (democracia). Este cierre ontológico lo produce el cortocircuito que se establece entre la Sorge o cuidado y la finitud del Dasein hasta el extremo de hacer de aquel existenciario ontológico-hermenéutico un cordón sanitario al cuidado del Volk alemán. Primero se rompe la dualidad alma/cuerpo o yo/cuerpo mediante una identificación absoluta con el propio cuerpo. Es el primer movimiento que cierra o destruye la subjetividad. Pero, dado que la ontología heideggeriana es esencialmente temporeidad en tanto que el tiempo como marco del Dasein $=$ Volk $=$ Staat $(\$ 77$ de Ser y tiempo $)$ no es otra cosa que la vuelta hacia el origen, Ursprung, ${ }^{3}$ a este primer cierre del alma

no reconoce prestigios personales. Sobre tal libertad se basa la misma existencia de la razón, la cual carece de autoridad dictatorial. Su dictado nunca es sino el consenso de ciudadanos libres, cada uno de los cuales tiene que poder expresar sin temorsus objeciones e incluso su veto" (Kant, 1978, p. 590).

${ }^{3}$ Véase la radicalización política de la vuelta al "inicio" de la existencia del Ser en los griego-alemanes en Martín Heidegger: "Europa y la filosofía alemana”. Conferencia dada en 
en su propio cuerpo le sigue un segundo cierre mucho más importante para la historicidad del Dasein ya que al cierre del alma o espíritu individual, singular, único, en su propio (eigen) cuerpo le sigue una fusión e identificación espiritual metafísica-y-política-de-el-cuerpo-propio-decada-Dasein-en-el-cuerpo-de-el-Volk-en-su-Estado. Y de la misma forma que el alma o espíritu o yo han dejado de ser una posibilidad de fuga trascendental y de apertura a lo otro, del mismo modo el Volkgeist de la hermenéutica de la facticidad histórica del Dasein se encamina, ya desde los años 20, a lo que agudamente Esposito denominó recientemente como "el cierre del cierre" (pp. 222-30).

Se trata, como hemos investigado en otro lugar, de lo que denomino como "el giro gótico nórdico-germánico" contra la filosofía moderna que, a su vez, viene de la interpretación judeo-cristiana del $\lambda o \gamma o \varsigma$ como "palabra", "asamblea", "argumento", "lógica" y por lo que su ontología tiene al espacio como categoría fundamental porque lógos implica una acción comunicativa entre personas que hablan y discuten precisamente en el lugar sagrado de la crítica: el aropa. Todo lo contrario a la pluralidad del logos que no es un a priori vacío de contenido sino la resultante espacial discursiva de la pluralidad ontológica misma, en dirección opuesta, frontalmente opuesta, al paradigma moderna de la subjetividad e intersubjetividad: Cervantes, Montaigne, Descartes, Spinoza, Leibniz, Locke, Hume, Montesquieu, Diderot, Voltaire, Kant, Stuart Mill y, en parte, Nietzsche, entre otros, el giro gótico nórdicogermánico plantea su ontología como el re-pliegue de la identidad sobre sí misma. Esta identidad es anti-monadológica no porque carezca obviamente de armonía preestablecida y su "lucha por el ser" la plantee, como hizo Heidegger en "Europa y la filosofía alemana", en tanto "aniquilación" del otro no-esencial; sino porque se despliega hacia dentro. Esta ontología y esta política del Ser quiere encastillarse (la metáfora no es casualmente feudal) en su ser mismo, en su puro ser mismo. Por lo que volvemos a conectar, desde un radio de acción más amplio y profundo, la hermenéutica de la autenticidad heideggeriana con la biopolítica del nazismo de corte inmunológico. Al respecto la tesis de Esposito tiene un antecedente muy clarificador en el trabajo

Roma en 1936. Tenemos una excelente traducción al español de Breno Onetto en internet: "Heidegger en castellano". En alemán se encuentra en la Gesamtausgabe [GA], Band 2 (1993), pp. 31-41. 
de Günther Anders titulado "Heidegger, esteta de la inacción". Esto no quiere decir que el ex discípulo de Heidegger tematizara como tal la biopolítica en la ontología heideggeriana; pero sí señaló de forma extraordinariamente temprana la "mezquindad" del ser sí mismo heideggeriano, el ser auténticamente un sí mismo, frente al hombre medio. El adjetivo empleado es de Anders y tiene su razón de ser tanto en la "automutilación" del ser humano que exige esta "filosofía de la vida hostil a la vida" como en la posibilidad que deja abierta esta tarea de autenticidad respecto a si cabe suprimir esa medianía (2008, pp. 65-11).

En Ser y tiempo el espacio público intersubjetivo de la fenomenología y de la democracia quedan destruidos en aras de un cierre ontológico estatatlizador, cuya noción de Estado, a su vez, no es otro que el de Estado étnico de la comunidad auténticamente alemana. Así quedó definido en 1927 este existenciario "destino común": "Con este vocablo [destino común, Geschick] designamos el acontecer de la comunidad, del pueblo" [cursivas en el original] (2003, p. 400).

Volk y Gemeinschaft son los existenciarios previos al Dasein, es más, el ser-aquí única y exclusivamente se desvela como perteneciendo al Volk. Esta pertenencia, cuyo origen está en el pre-romanticismo alemán como búsqueda de una pura tradición perdida así como la vuelta a unas raíces "populares" que, por culpa de la modernidad -común denominador entre Herder, Heidegger y Gadamer-, ${ }^{4}$ este sentimiento de pertenencia a la patria de origen, Heimat, Vaterland, está a punto de desaparecer al entrar en contacto "la nostalgia secreta del alma alemana" (la frase es de Levinas en Algunas reflexiones sobre la filosofía del hitlerismo, 1934) con la reflexión crítica del concepto cuya tarea es, en palabras de la Fenomenología del espiritu de Hegel, analizar a fondo aquello precrítico, antimoderno, en donde aspira a situarse para siempre el alma o espíritu basado en la autoidentidad del yo $=y o$. Es desde esta autoinmunización ontológica del ser auténtica alemán en su comunidad o Volk desde la que Heidegger sueña una nueva identidad para la Alemania de la derrota de 1918. Un nuevo ser que de ninguna forma pudiera conectarse a las ideas filosóficas y políticas del

${ }^{4}$ Dos investigadoras mexicanas han llevado a cabo, al respecto, una inapelable investigación de las profundas conexiones entre la hermenéutica alemana y el nacionalsocialismo (Orozco, 1995). 
mundo moderno ya que el resentimiento cultural y político ante la victoria del mundo civilizado le impedía tomar conciencia alguna de la realidad del mundo moderno. La ontología heideggeriana era, pues, un callejón sin salida para el pueblo alemán. O dicho en términos más heideggerianos: al Volk alemán para ser lo suficientemente auténticamente alemán sólo le quedaba una salida: la "vuelta" al origen, ese sueño metafísico (en el sentido del estar siempre, los 365 días del año y el resto del Eterno Retorno interrogándose "¿Por qué hay Seyn y no más bien Nada?") y patético de la autoidentidad acorazada que provocará el cortocircuito de la más elemental prudencia política. La huida hacia el abismo que defendió Hitler en su plebiscito de 1933 gracias a lo que Alemania salía de la Sociedad de Naciones tenía un fundamento ontológico con la salida de Heidegger de la filosofía moderna y su instalación en un nuevo naturalismo de carácter existencial-histórico: o Todo o Nada.

Volk= Staat era la salida pensada por Heidegger para la Alemania de la derrota. Contra la derrota del origen más origen si cabe. La salida se constituye ontológica y políticamente como un cierre sobre sí mismo, sobre el pasado que ha degenerado la modernidad y la decadencia de Occidente. La Kehre o "vuelta" que propone Heidegger desde el paisaje de la Selva Negra hace de conciencia para muchos miles de alemanes completamente desorientados tras la caída del III Reich. Y, bien mirado, ahí puede estar la razón de que Ser y tiempo fuera un éxito para su época como si el ser auténticamente alemán fuera realmente para la muerte. Pero esta estructura existencial tan patética y pedante de pose académica y tonalidades tan lúgubres en donde Dioniso (y la risa, y la hermandad, y la amistad, y los afectos, y el cuerpo, la sexualidad, etcétera) relumbra por su ontológica ausencia, pero estos existenciarios, decía, se van haciendo cada vez menos "ideas" (si es que alguna vez estuvieron dentro de la teoría) para desvelarse como "fuerza" $[$ Kraft $]$ propia que da el origen-epicentro de un pueblo racial. Es en este contexto en el que el análisis del ser se hace deudor absoluto y enteramente "encadenado" ${ }^{5}$ del pasado o herencia o "bienes patrimoniales” - tal y como traduce sin el menor escrúpulo científico filológico

\footnotetext{
${ }^{5}$ Emmanuel Levinas: Algunas reflexiones sobre el hitlerismo, pp. 7-21. Al tratarse de un breve ensayo cito todo el texto. Su discípulo Miguel Abensour sí hace un análisis pormenorizado en la segunda parte de este libro: El Mal elemental. FCE. México, 2006.
} 
el término griego ovøı (Heidegger, 2000) que desde la situación hermeneuta de la "existentia" se conocía como "sustancia" y, por ende, era

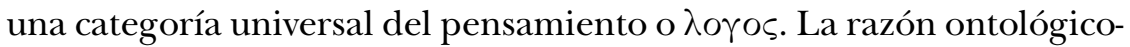
hermenéutica de que Heidegger entienda su hermenéutica "teoría de la verdad" existencial como "repetición" [Wiederholung] del origen del Dasein. ${ }^{6}$ Lo que, a su vez, nos aclara el significado ontológico-nacional o "nacional-esencialismo" con el que acaba de rebautizar Henri Meschonick el "pensar" [Denken] heideggeriano, que late como intencionalidad plenamente cerrada del Dasein en su Volk al definirse, como hemos visto, el destino común no como una elección que hacemos entre todos, y con bastantes conflictos e imposibilidad de una síntesis absoluta o palabra última del origen; sino que es la voz del pasado lo que habla por nosotros. Y, de ahí, que Heidegger afirmara también en el cap. 74 lo siguiente:

Con esta palabra [destino, Schiksal] designamos el acontecer originario del Dasein que tiene lugar en la resolución propia, acontecer en el que el Dasein, libre para la muerte, hace entrega de sí mismo a sí mismo en una posibilidad que ha heredado, pero que también ha elegido [cursivas en el original] (2003, p. 400).

De esta forma el carácter existenciario de la muerte "sella" (Prägung) la finitud y el modo propio (Eigen, Eigentlichkeit= en propiedad exclusiva) de existencia que tiene el Dasein-Volk-Stäat (\$77). El pueblo alemán, según Heidegger y como cualquier investigador puede comprobar al releer Ser y tiempo desde el final hacia delante, no sólo tendría en patrimonio $(o \cup \sigma \downarrow \alpha)$ exclusivo la existencia sino también la muerte. El Volk no toma conciencia de la muerte como si fuera un suceso de la naturaleza humana o de la vida humana que todos compartimos; sino lo que sella la diferencia ontológica entre, $\$ 9$ de Ser y tiempo, el existenciario alemán Existenz y ese otro modo de (no) existencia que calificó Heidegger con el latín existentia. Una cosa es "ser-aquí" y otra, radicalmente incompatible con la primera, "estar-ahí" [Vorhandenheit] como Polonia. ¿Qué diferencia a la Existenz alemana de la subhumana existentia moderna?: la "falta de suelo" -Bodenlisigkeit, cap. 77-, que tiene el pensamiento moderno a partir del giro copernicano y su

\footnotetext{
${ }^{6}$ La obra de Martín Heidegger que más espacio dedica a esta teoría de la verdad como
} "repetición" del origen es Introducción a la Metafísica. 
consecuencia nietzscheana del "Dios ha muerto" que coloca al hombre desde el Renacimiento ante una mar infinita y a la vida transformada en una "X", en una incógnita que nos anima desde dentro del mismo

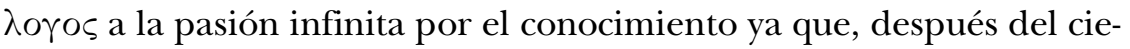
rre geocéntrico y escolástico sobre el mundo y el hombre, cabe anunciar una nueva buena: que la vida, el mundo, admite desde sí mismo una infinitud de interpretaciones... hasta el punto de que la mar, el océano del universo, nunca había estado ahí delante con un horizonte tan infinito. ${ }^{7}$

El capítulo 6 de Ser y tiempo se titula "La tarea de una destrucción de la historia de la ontología”. Si Derrida y Vattimo hubieran leído esta obra como les indico, de atrás -que es el "origen" y "suelo" (Boden)hacia el equívoco inicio del libro con el Dasein como si este existenciario pudiera nombrar aún un individuo, yo, persona, alma o espíritu entendidos como categorías de la filosofía moderna, si estos maestros, y amigo en el caso del italiano, se hubieran tomado en serio la intencionalidad que late en el término alemán Destruktion, de seguro que se lo habrían pensado dos veces antes de interpretar la hermenéutica heideggeriana como "deconstruccion" y "pensamiento débil". A mi juicio se equivocaron al creer que la hermenéutica aristotélica de cuidar heideggeriana o salvar la albergaba pluralidad la de buena intención perspectivas e interpretaciones que es la vida humana y la historia de la filosofía. Pero, hay que volver a repetirlo, Ser y tiempo no tenía, ni mucho menos, la tarea de salvaguardar a todos los pueblos como se cree entre los heideggerianos mexicanos - "Por mi raza hablará el Dasein" que escribe Guillermo Hurtado en Dos mitos de la mexicanidad-, que suspiran por la tradición auténtica y han conseguido transformar el racismo ontológico de Heidegger en un antecedente hermenéutico de El laberinto de la soledad (Habermas, 2001). Lo mismo ocurre con los heideggerianos españoles "autonómicos" e "independentistas" de los nacionalismos periféricos para quienes "la lengua es la casa del ser" tiene una prioridad ontológica frente a la Constitución política democrática, anteponiendo en estos casos un patriotismo lingüístico al "patriotismo constitucional" que reclama Habermas para vivir entre personas diferentes (Habermas, 2001). Tanto en el caso español como en el mexicano (francés o argentino o chileno) la vuelta atrás les obliga

${ }^{7}$ F. Nietzsche: La Gaya ciencia: $§ 124$, En el horizonte de lo infinito. 
a torcer la verdad histórica a su capricho y a tener que inventar la gran mentira del origen.

Pero todo esto sólo es producto de una lectura de Heidegger absolutamente descontextualizada; y no me refiero a nivel histórico-político, lo que es evidente, sino, menos señalado, a nivel filosófico ya que no han tenido en cuenta las profundas influencias que tiene el conde Paul Yorck von Wartenburg en la crítica del pensamiento moderno como un pensamiento "desarraigado", sin suelo nacional del origen cuya imagen del mundo y del hombre se debe a la racionalidad judía de orden eminentemente abstracto, universal y cosmopolita. La destrucción de la subjetividad moderna -el "yo", el "sujeto", el "alma", el "espíritu", la "razón”, la "persona” y... la República de Weimar, era la condición "sine qua non" para reestablecer la auténtica subjetividad del Volk y del Estado étnico. Desde este contexto a nadie debería extrañar, pues, que en el mismo capítulo 6 de $S u Z$ que se anuncia la tarea de una "destrucción de la historia de la ontología”, en ese mismo capítulo, Heidegger pueda exigir como parte de la ontología de la temporalidad del Dasein, la "demostración del origen [Ursprung] de los conceptos ontológicos fundamentales del pensamiento griego”. El término alemán que re-define en 1927 la tarea hermenéutica de la facticidad histórica del Informe Natorp de 1922 es Geburtsbriefen: "certificados de nacimiento". Sí, es verdad, parece increíble pero lo tenemos en la página 32 de la edición del Fondo de Cultura Económica y en la página 46 de la de Trotta, así como en alemán en la página 22 de la edición Max Niemeyer Verlag. Hasta donde he llegado leyendo ningún especialista ha señalado esta "casualidad" del Zeitgeist nacionalsocialista con el espíritu de esta hermenéutica inmunológica. El caso es que en 1933, en el Discurso de Rectorado, menos de seis años después de su obra maestra, el existenciario Sorge o cuidado ocupa el papel principal en la escena política del III Reich ya que, según Heidegger, la auténtica "ciencia" es la que cuida del acervo patrimonial (la ovøı $\alpha$ de 1922: "bienes patrimoniales") del Volk alemán; en otras palabras, por encima de las ciencias de la naturaleza tienen que estar las ciencias del espíritu 
cuya "intencionalidad plena" o Sorge $\mathrm{e}^{8}$ consiste, afirmó Heidegger, "en el cuidado de la sangre [Blut] y de la tierra [Boden]". ${ }^{9}$

\section{Acercamiento fenomenológico y biopolítico a la Hermenéutica analógica de Mauricio Beuchot Puente}

En el tomo ir de La vuelta al día en ochenta mundos del gran fenomenólogo argentino Julio Cortázar leemos lo siguiente:

Si conocer alguna cosa supone siempre participar de ella en alguna forma, aprehenderla, el conocimiento poético se desinteresa considerablemente de los aspectos conceptuales y quitinizables de la cosa y procede por asalto e ingreso afectivo a la cosa. Lo que Keats llama sencillamente tomar parte en la existencia del gorrión y que después los alemanes llamarán Einfühlung, que suena tan bonito en los tratados [negitas en el original] (p. 173).

La hermenéutica analógica no está obsesionada ni con el mito de la identidad, ni con las mistificaciones de las diferencias. Para Beuchot el texto no es un objeto de culto ni un pretexto para hacerle decirle al autor lo que jamás hubiera dicho. Una hermenéutica potable no tiene más remedio que ser sutilmente analógica si es que quiere hacerse cargo del texto del mundo. Un texto que, además de estar escrito en caracteres matemáticos, también lo escribe la carne convertida en sujeto y objeto de nuestra trama narrativa. Todos somos, en alguna medida, parte del texto del mundo.

Esta "polisemia" de Lebenswelt, esta infinita riqueza de pluralidad, es el fundamento ontológico y ético de una hermenéutica que, a la vez que "interpreta", nos "traduce" y construye puentes entre las diversas orillas. El hermeneuta analógico se sabe parte de un diálogo infinito sin fronteras; de forma que el rigor ético interpretativo se constituye fenomenológicamente en calidad de imperativo categórico: forma parte de un fin en sí mismo. Y si se destruye puede que desaparezca no sólo la intencionalidad del autor sino el autor mismo. ¿Acaso significa

\footnotetext{
${ }^{8}$ La obra de juventud en la que de forma más clara transforma Heidegger la "intencionalidad de la conciencia" en "intencionalidad plena" o Sorge es el Informe Natorp de 1922. Esta plenitud del ser lo es contra la falta de suelo del "Pienso, luego existo" cartesiano de carácter universal.

${ }^{9}$ Los llamados Escritos Políticos de 1933 y 1934, no son, como suele creerse, una invención de los antiheideggerianos; sino que se basan en el volumen 16 de la Gesamtausgabe. Cfr. F. Fèdier: Heidegger. Ecrits Politiques 1933-1966, Gallimard, Paris, 1996.
} 
otra cosa la quema de libros por parte de la Inquisición española y del nazismo?

Por esta razón es que debe imponerse cierta $\psi p o v \varepsilon \zeta \zeta$ o "prudencia" que exige todo diálogo e intercambio de ideas. En efecto, la interpretación de un texto no puede darle la espalda al "contexto" desde el que brotó; si se menosprecia su contexto es porque lo que alimenta el espíritu del intérprete no es la de salvar la vida o la historia, recrearlas desde nosotros mismos, sino su desaparición parcial o total. La hermenéutica analógica pertenece, entonces, a ese marco teórico en donde la historia de la filosofía tiene que ver no con "fuerzas" sino con "ideas" y, a su vez, anuncia de forma implícita una biopolítica que afirma normas desde la vida. Es más, al ser una biopolítica analógica de $\tau \varepsilon \lambda o \zeta$ universal e infinito puede señalar las diferencias desde sus vasos comunicantes, "sustancia", exactamente lo contrario de lo que persigue la hermenéutica inmunológica del origen de la ontología heideggeriana del Dasein = Vollk.

Creo que podemos decir que este Tratado reconstruye el daño que en el siglo $\mathrm{xx}$ han ocasionado a la vida tanto el lenguaje totalitario comunista del cuerpo abstracto como el lenguaje völkisch del totalitarismo nazi. Pero, a mi juicio, el hecho bio-bibliográfico de que este Tratado de hermenéutica no cite - ni para bien ni para mal- a Heidegger nos señala, sin necesidad de psicoanálisis, que así como la ontología del filósofo nazi rompe el continuum de la vida y de la historia, la "analogía" vuelve a tejer pacientemente las tramas del texto hecho

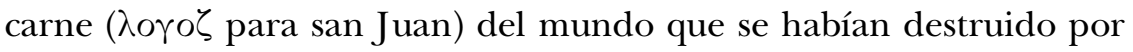
el mestizaje cultural y existencial del ser. Es contra éste mestizaje del ser hebraico-greco-latino-cristiano-moderno por lo que se escribe Ser y tiempo. Y ante el panorama hermenéutico en el que vivimos la voz de Beuchot, este filósofo y dominico mexicano, se alza con valentía para restituir a la "sustancia" a su orden prioritario humanista, defendiendo una hermenéutica que no venga a seguir ahondando en nuestras diferencias y canalladas ni en nuestros igualitarismos igualmente asesinos que se han padecido política y filosóficamente en el siglo xx.

Ahora bien, la "hermenéutica analógica" implica la existencia de la "pluralidad" de la polis en la misma medida en que Aristóteles, frente al "univocismo" reductivista de las almas a las tres almas bien diferenciadas de la República de su maestro, había fundamentado su virtud 
política esencial, la "prudencia" entre fines y medios, en una ontología de la contingencia de los asuntos humanos. Por lo que no es de extrañar que Beuchot quiera -es mi idea interpretadora principal- una hermenéutica de los textos haciendo hincapié, es verdad que de forma oblicua, en el olvido manifiesto de Heidegger cuando en la década de los 20 interpretaba "audazmente" desde su "fuerza" [Kraft] interpretadora el Libro vi de la Ética a Nicómaco despreciando olímpicamente la importancia de la "prudencia" para el Estagirita.

Son dos políticas hermenéuticas completamente opuestas; aunque Beuchot intente analogizar este trasfondo heideggeriano desde Gadamer. ${ }^{10}$ Creo que ahí tiene la hermenéutica analógica un escollo filosófico muy importante. De la misma forma, como afirma Beuchot, que no todas las interpretaciones valen lo mismo; de igual medida, pero desde la prioridad kantiana de la razón práctica sobre la razón teórica, el intento cordial de la analogía tiene que poner una barrera (que sólo puede venir de la objetividad de la "verdad histórica") frente a los abusos actuales hermenéuticos gracias a lo que se disuelve la diferencia entre "víctima" y "verdugo".

Una hermenéutica que se declara abiertamente analógica no va a gustar a los nacionalistas porque la analogía, decíamos, traza puentes entre las dos y ochenta vertientes de nuestras vidas. Este Tratado no sirve como manual de, para decirlo con Amin Mahlouf, "identidades asesinas". Al revés, la "empatía”, Einfühlug, nos anima a salir de nosotros mismos y participar afectivamente de la realidad de otra persona. Se trata de un esfuerzo metafórico, alas como abismos, mediante el que nuestro cuerpo se espiritualiza hasta en las uñas para acudir a la cita del texto, ya sea una cita a ciegas o académica, y ponernos a tomar café, echar un puro en mi caso, platicando con ese "alguien" que nos interpela desde el siglo iv antes de Cristo o desde la última novela de Javier Marías.

Desde mi punto de vista, y recordándoles que sólo he tematizado los dos primeros capítulos de este tratado, el fundamento ontológico, ético, político y estético que se ha dado a la hermenéutica en su

\footnotetext{
${ }^{10}$ Mauricio Beuchot: Tratado de hermenéutica analógica, Facultad de Filosofía y Letras, UNAM/Editorial Ítaca, México, 2005. En algunos aspectos me he guiado por el excelente trabajo de Jacobo Buganza: Ensayos sobre hermenéutica analógica. RIHB/Editorial Torres Asociados, México, 2012.
} 
cruce vital, i"la cita" con los otros!, como esencia renovadamente humanista del Juego del mundo, nos devuelve la confianza en la filosofía y tanto frente al modo de citar que tiene el rigor mortis académico como a la disolución del autor con la que proceden temerariamente posmodernos y relativistas. Así, cuando en la p. 24 se recalca que hay que "respetar al autor" y que "el texto ya no dice exactamente lo que quiso decir el autor [porque] ha rebasado su intencionalidad al encontrarse con la nuestra", este autor se une a esa larga lista de autores modernos y antifascistas que van desde Husserl a Ortega y Unamuno, de Merleau-Ponty a María Zambrano, de Georges Canguilhem a Simondon pasando por Roberto Esposito, unidos, por encima de sus diferentes áreas de conocimiento, por una misma intencionalidad de la conciencia filosófica liberal humanista: deshacer todos y cada uno de los "cierres" anti-filosóficos creados en el siglo xx como parte sustancial de la violencia metodológica.

En el marco histórico de la hermenéutica construido por Heidegger todos estos males y catástrofes se reducen a uno: la mística retórica de la "violencia" como fuerza espiritual necesaria de una teoría ontológica de la cultura para la que en el principio no era el $\lambda o \gamma o \zeta$ sino la acción, la fuerza y el ciego poder.

Una hermenéutica que vive entre varias lenguas como pez en el agua, que traduce al otro para que se nos aparezca la buena, jovial y misericordiosa $\alpha \lambda \eta \vartheta \varepsilon\llcorner\alpha$ como des-velamiento de los otros de los que participamos afectivamente, que vive de forma analógica, empática, la vida del Logos que va desde los conceptos fundamentales de la Filosofía política a los huevos rancheros, de Bach a Chavela Vargas, del desierto del Sáhara al Mediterráneo tangente de Málaga, es una hermenéutica que ha rebasado la nostalgia y melancolía pre-moderna y romántica de El laberinto de la soledad. Esta hermenéutica no se antepone a la pluralidad de la vida del texto que entre todos vamos escribiendo y rescribiendo con no pocas tachaduras como en la Escuela.

Por último. Encuentro un aire de familia entre el Tratado de hermenéutica analógica y Las fuentes del yo de Charles Taylor (1998). Me explico. La identidad, nuestras identidades como personas, puede construirse de dos formas; una es la que llamaré identidad fundamentalista, todo un paradigma antimoderno, antisubjetivo, gracias a la que el yo responde ipso facto a una determinada y unívoca tradición, sea cual 
fuere, laica o eclesiástica. Esta fuente del yo y del nosotros es de orden esencialista: prima a la Idea o bloque por encima de lo particula y concreto de cada vida humana. En este paradigama se confirma el cierre ontológico del ser sobre sí mismo, "el cierre del cierre" del que habla Esposito pero haciendo hincapié en el dogma-círculo de un mundo circundante que se blinda a sí mismo desde sí mismo contra lo otro. Este paradigma es monocromático, monotonoteista y monológico. Y, políticamente, está, ontológicamente, contra la democracia liberal o perspectivismo democrático. Mientras que el siglo xxi alumbra, en la estela de una modernidad que aún no es, que no podrá ser como lo supusieron Hegel y Marx (y Stalin): sólo lo racional es lo real, porque la realidad del mal nos obliga a volver de forma infinita a Kant, al Kant de la eterna diferencia entre fenómeno y noúmeo, al Kant de la Dialéctica Trascendental como horizonte infinito del Logos-Mundo (Husserl, Merleau-Ponty), mientras que hay una segunda opción ilustrada siglo xxI de construir nuestra propia identidad tal y como el pintor va utilizando los colores de su paleta y pintando un autorretrato cuyo rostro y expresión han surgido, milagrosamente, del marco infinito que late en la conexión entre los colores. Lo mismo puede ocurrir con la música. De tan sólo siete notas podemos construir una música infinita. Pues bien, ¿̇por qué no aplicar este paradigma de extraordinarias inter-conexiones para ir construyendo nuestra mismedad con la ayuda de elementos distintos a los de nuestra propia cultura e historia? Al modo como el pintor juega con la multiplicidad implícita que late en su paleta, nosotros podríamos hacer el esfuerzo del Sapere aude! en plena revolución siempre penúltima de la ciencia y técnica del conocimiento global, intercultural, intercomunicativo, en el que, al menos en Occidente, ya estamos "arrojados". Gracias a la posibilidad real, no sólo de ficción, de salir y entrar en una cultura con el ánimo de aprender algo nuevo para uno mismo, un ritmo, una oración (otro tipo de ritmo), una comida agradable, un vino generoso, una amistad bilingüe y un amor apátrida, un amor hacia las personas por encima del Estado nacional (Habermas), ahora tenemos la oportunidad que nunca tuvieron los sofistas: conversar con todo el mundo a través de internet. Nunca habíamos tenido tan cerca al otro.

La primera manera de construir el yo es la univocista y heideggeriana; aquella identidad que te encadena a la repetición de tu propio 
origen y procedencia; $\$ 74, \S 75, \S 76$ y $\$ 77$ de Sein und Zeit, propia, pues, de una hermenéutica inmunológica. Mientras que la segunda es propia de la $H A$, de la hermenéutica analógica que, por encima de las diferencias, aún teniendo en cuenta la diferencia, traza puentes para salvar ese abismo insaciable de poder que se va gestando ontológica y políticamente en el solipsismo. A partir de ahí le propongo a Beuchot que incluya en su firma de autor a su madre: Puente. Tal vez ahora se entienda mejor por qué Albert Camus, en plena Resistencia francesa contra la ocupación de Francia por los nazis, afirmó que entre el estado y su madre elegía a su madre como puente para la vida en libertad.

\section{Hermenéutica analógica y hermenéutica débil: el malentendido}

Escribo ahora en base a la lectura parcial del libro de Mauricio Beuchot, Gianni Vattimo y Ambrosio Velasco Gómez titulado Hermenéutica analógica y Hermenéutica débil "A pesar de las divergencias" (p. 11): así plantea Beuchot Puente su diálogo crítico con Gianni Vattimo. Y ese va a ser nuestro leit motiv. Hay muchas analogías entre el pensamiento débil y la Hermenéutica analógica (HA). Hay un equívoco y, a la vez, unívoco conflicto que hermana, en parte al menos, a ambos filósofos contemporáneos: una visión de la modernidad un tanto unilateral, roma, centrada exclusivamente en el positivismo. Es posible rastrear en los dos autores una crítica a la modernidad demasiado esquemática, simplificada, mutilada -muy especialmente en el caso de Vattimo. Es lo que el propio Beuchot Puente dice de la modernidad en la que piensa el posmoderno italiano: "la modernidad sostuvo un concepto de razón monolítico" (p. 11). Pero ¿̇de qué modernidad se habla? ¿Era monolítica la novela de Cervantes El Quijote?, ¿̇eran monolíticos los Ensayos de Montaigne?, La razón del errante Spinoza era una razón "fuerte" como suponen uno y otro hermeneuta? ¿Qué se entiende por "metafísica occidental"? (p. 12). Se tiene la impresión de que se trata de una modernidad arreglada para ser vapuleada desde la tesis que afirma que la modernidad no tuvo en cuenta las diferencias y que todo fue mecánica y uniformización técnica del trabajo en los talleres y fábricas visitados por Marx en el Londres del siglo xix.

Esta atalaya de interpretación antimoderna parece tender un puente entre Vattimo y Beuchot cuyo mapa conceptual conocemos: Nietzsche, Heidegger y Adorno. Aquella razón monolítica habría llegado a 
su fin, "Dios ha muerto", y el sujeto y la verdad representacional han de dejar paso al "expresionismo" de las "vivencias" si yo. Gadamer en Verdad y método sólo tomaría en cuenta la phrónesis o prudencia de la Ética a Nicómaco para equilibrar la interpretación "fenomenológica" llevada a cabo por Heidegger de la ovoเ $\alpha$ aristotélica.

Ya no hay texto, ni sujeto, ni objeto. Así, pues, la razón se retira, diríamos, para dar paso al "pensamiento débil". Pero, en nuestra opinión, ${ }^{11}$ y según estas coordenadas filosóficas, el padre o abuelo filosófi-

11 "La filosofía de Schopenhauer es una imparable resta ontológica que llega hasta la nada. Razones no faltan; nadie como este autor ha señalado la radicalidad del mal. Tanto las 'almas atormentadas' como los 'diablos atormentadores' se deben a una misma voluntad de vivir. 'Vida' significa injusticia, crueldad y sufrimiento. No es menos cierto que tampoco se escatima pólvora a la hora de criticar la explotación; bastaría recordar el pasaje sobre el trabajo en las fábricas de tejidos 'donde las personas son atrapadas desde los cinco años, primero 10 horas, después 12, hasta 14 horas ejecutando el mismo trabajo mecánico', para concluir: 'He aquí lo que se llama comprar caro el placer de respirar'.Las reducciones del ser comienzan ahí. Como el origen del mal está en la pluralidad de focos de apetencia de poder que, engañados, ignoran el fondo metafísico de su igualdad, se construye una escala de valores que impele desde la 'virtud' a la 'estética' para triunfar en el 'ascetismo' porque aquéllas no desindividualizaban bastante. Esta solución 'nihilista' venía a ser, precisamente, la finalidad real de la vida: la insuperable maldad y la reflexión que ella origina muestran la razonabilidad del dejar de ser. La contradicción de esta filosofía (otro día hablaremos del piadoso ascetismo del autor al ofrecer sus anteojos de teatro para que se disparara mejor desde su balcón contra las barricadas en los acontecimientos de 1848) está en el oscilante estatuto que se le da a lo individual: mera apariencia. Pero si el mal es tan radical, ¿por qué los individuos son meras ilusiones? Contradicción que gana en interés cuando en su giro nominalista niega rotundamente la pretendida 'unidad de marcha' de la historia.

Este problema no es ajeno a la ontología / teología que pretende defender al individuo mediante la idea general de la ascesis. Pues toda ascética -decía Nietzsche- significa 'una crianza para la impersonalidad, para olvidarse-a-sí-mismo'. ¿Será la 'ontología débil' la fuente donde los nuevos mandarines de la ascética de la época de la técnica nos mandarán beber para luego redimirnos por el 'olvido'? Pero lejos está Nietzsche de escapar del dilema. Porque es innegable que desde 1878 y frente a la explotación del trabajador no proponía la debilidad, sino la acción: 'No eludir la aventura, ni la guerra, y tener preparada para las contingencias más graves la muerte, con tal que cese esta servidumbre indecente, este volverse agrio y rencoroso y subversivo'.

Ahora bien, junto a esto aparece la contradicción que tenía que aflorar desde el mítico origen del mal. Pues, tras exhortar a la 'rebelión' y a la 'salida' de Europa y hacer de la pérdida del miedo a la muerte (Hegel) el auténtico umbral de la emancipación, acaba afirmando que, además, iqué importancia tiene la escasez de la mano de obra... si todavía están los chinos! Se necesitaría ser nietzscheano de comunión diaria para ocultar estas cosas y poder presentar la cara liberalizadora del vilipendiado Nietzsche. Afortunadamente, G. Vattimo está en las antípodas. Sin embargo, en la radicalidad y sinceridad de tales contradicciones estriba la diferencia irreductible entre discípulo y maestro. Porque el desconsolado, pero noble, anacoretismo al que se somete desde el Zaratustra $\rightarrow$ y que puede confundirse con la prédica de la ascesis schopenhaueriana- es fruto de la impotencia a que el fracaso de la idea de Comunidad, nada raro entre los humanistas alemanes, le ha obligado. Desde esa atalaya creyó realmente que 'el despreciable sistema capitalista caerá con sólo despreciarlo'. 
co de Vattimo no sería Heidegger sino Schopenhauer. Pero tengo razones para dudar sobre esta hipótesis, ya que Vattimo se ha centrado en la ontología y hermenéutica de Heidegger, especialmente Ser y tiempo;

Lo que se olvida es que a Nietzsche no sólo lo salva esta bendita ingenuidad, sinotambién su falta de compasión. 'Nihilismo' significa políticamente desvelamiento de las raíces identificadoras, entre razón y dominio, lo que implica que el hombre sea el único animal capaz de decir 'ino!' Por lo que no es el ascetismo, sino esta capacidad para negar, lo que devuelve la confianza en el hombre. Frente al posmodernismo que propone la interpretación del 'final' de la filosofía como el toque de queda para dejar de pensar, acaso quepa reflexionar aún sobre el origen de su propia debilidad en relación, con el ocultamiento radical del proyecto de subjetividad de la modernidad.

Kant pensaba en 1784 (Qué significa orientarse en el pensamiento) que el abandono de la máxima sobre la 'independencia' de la razón, renuncia que denominó descreimiento racional, no podía ser histórica ni, por tanto, 'imputable'. Pero la debilidad que hace gala de la llamada 'cura de adelgazamiento del sujeto' ¿no acabará transformando este descreimiento, que sólo debía ser producto 'pasajero' del estado penoso del ánimo humano, en historicismo? Si esto llega a cristalizar la 'tarea' al 'final' de la filosofía estaría bien clara: no se trataría de abandonar un 'criterio de opción' por otro, sino por ninguno. Contra esto se proponía el Sapere aude, que no implicaba tanto una autotransparencia social absoluta como valor para llevar a cabo lo que sólo podía ser una tarea infinita. Consciente de la debilidad congénita del hombre -verdadera opacidad frente a todo ideal-, se nos insta a que tengamos resolución para servirnos de nuestro propio entendimiento contra la 'pereza' y la 'cobardía' que anclan en la 'minoría de edad'. Y no caben dudas hipócritas. El 'uso público' de la razón tenía para Kant a los mismos detractores que en el 'final' de la modernidad: el militar, el banquero y el pastor para quienes podemos 'razonar' de todo lo que queramos, pero siempre que se acabe obedeciendo. ¿Cómo explicarles a éstos la postura 'debilista'? ¿No se está confundiendo nuestra general falta de ánimo con la necesidad urgente de desarticular del todo el proyecto de la Ilustración? ¿Es de extrañar, como comentaba Habermas, que los neoconservadores reclamen la necesidad de una política orientada a quitar la espoleta del contenido explosivo de la modernidad cultural? Lo que había comenzado como una oportuna crítica a la subjetividad del modernismo academicista está acabando en un desmantelamiento de la subjetividad e individualidad frente al sino de la técnica. Por ejemplo, las posmodernas teorías sobre la escritura que con el ánimo de entrada de reconducir el tema de la relación ontológico política de la multiplicidad /unidad, fragmento /todo, hacia una liberación de la escritura frente a la momificación del concepto, puede concluir en que todo es Gramáticade-la-máquina-de-escribir-de-El-Corte-Inglés. El autor ya no es autor, ni el lector es ya lector. Vale. Pero mientras alcanzamos un nuevo tipo de subjetividad, no sólo para leer, sino para vivir, el mundo tecnocrático anda frotándose las manos: ahí tienen el sustituto de la ilustración que andaban buscando, perfecta adecuación para la abstracta uniformidad que se impone. ¿No tiene esto relación con la llamada -justamente al levantarse acta de la defunción de la modernidad- hacia el ascetismo y la desindividualización? ¿Y qué decir del socialismo (posmoderno) que remite a la eterna paciencia (¿de quiénes?) para resolver los conflictos? Es por lo que pienso que la 'ontología débil' potencia la realidad social del mal que, conocedora del nihilismo piadoso del 'final' de la filosofía (a mí me suena que Nietzsche pedía desesperación antes que resignación), se atrinchera de nuevo entre la apocalíptica imposibilidad de ir construyendo una sociedad más razonable y nuestra propia renuncia.

Y estoy convencido que nadie menos que un profesor tiene derecho a jugar con las apologías de la desesperación. Se puede ofrecer la otra mejilla. Siempre y cuando, como explica Borges, no nos mueva a ello el temor". Julio Quesada: "Posmodernismo y debilidad". El País, 25 de junio de 1987. 
y, a su vez, es desde este "legado" existencial-histórico aparentemente neo-humanista desde el que surgen las divergencias más profundas entre HA y la hermenéutica débil (HD).

Creemos que existe en la interpretación posmoderna de Heidegger un error de bulto. No quiere esto decir que nosotros tengamos las llaves del reino de la verdad; pero sí anhelamos saber la verdad. Esta verdad o, mejor, esta "teoría de la verdad" como des-velamiento, alétheia, des-ocultamiento de lo "encubierto" por una mala o "impropia" o "inauténtica tradición" de la interpretación del ser hebraicolatina-cristiana-moderna, ha traído como consecuencia un error. La traducción que suele hacerse de lo que en Ser y Tiempo aparece como "falta de fundamento" [Bodenlosigkeit: Ser y Tiempo, $\$ 6$ y $\$ 77-$ por ejemplo-] hace creer a la posmodernidad de Vattimo y Derrida en la tesis de que la superación de la metafísica del sujeto apuntó, final de la filosofía moderna, a una metafísica sin subjetividad alguna, puro Nihilismo. Hoy sabemos que esta interpretación no se sostiene porque lo que lleva a cabo Heidegger es una transformación o cambio de una subjetividad individual por una subjetividad colectiva o comunitaria en el sentido de "comunidad" [Gemaischaft]. No es que ya no haya "sujeto" o "subjetividad"; sino, más bien, que el centro de gravedad del ser se ha desplazado de lo individual-concreto, la conciencia, yo, o persona, al Volk, a la comunidad del pueblo. Lo tenemos en la última parte del libro: $\$ 74, \S 75, \S 76$ y $\$ 77$.

Si leemos Ser y tiempo quedándonos exclusivamente con la analítica del Dasein, ser-aquí, a modo de un individuo, sujeto o persona -lectura equivocada porque lo prohíbe, precisamente, la "destrucción" de las categorías de la filosofía moderna como, y cito, "yo", "individuo", "sujeto", "alma”, "espíritu", "razón” y "persona” (\$6)-, dejamos fuera el legado comunitario-nacional al que, frente a la Aufklärung, el dasein está encadenado desde el "origen" [Herkunft]. Es el peso de la tradición lo que, ahora, sustituye al "Pienso, luego existo". Heidegger desarrolla, entonces, un nuevo tipo de subjetividad, o hace renacer un nuevo tipo-mito de subjetividad que es el mito del origen del Fasein en su Volk. Es la historicidad de los "pueblos históricos" el sujeto de la historia y no un vector abstracto, Trascendental (kantiano, hegeliano, marxista) a su "propio" e "irreferente" fundamento. Pero al traducir y al interpretar, pues toda traducción es ya de por sí una decisión in- 
terpretativa, el término alemán Boden como "fundamento" seguimos la estela de la que Heidegger se quiere desmarcar por completo: ni idealismo, ni materialismo; sino existencia pura.

En efecto, la traducción de Boden por "base" que hizo José Gaos todavía podía acercarse más a la verdad de la traducción que no es otra que "falta (o ausencia) de suelo". Heidegger ya no estaba soñando con un mundo teórico, abstracto, sino con la existencia o Dasein, ser-aquí. Él mismo, y siguiendo literalmente al conde Yorck von Wartenburg (\$77), estabelicó una diferencia ontológica entre existencia auténtica o Existenz y existencia inauténtica o Vorhandenhait que suele traduicirse como "estar ahí". Sin embargo, la diferencia ontológica no justifica las interpretaciones de Vattimo ni la de Derrida. No ha muerto, ni mucho menos, el sujeto, sino que ahora se des-vela o se des-oculta en su nueva realidad existencial histórica: el ser es el Volk y se supone que todo Volk tiene un Boden, un suelo desde el que se yergue el Dasein= Volk= Staat [\$74 y $\$ 77)$.

El malentendido posmoderno está, pues, servido con esta "ausencia de fundamento" (que Beuchot señala en las páginas 14 y 15) que ha dado pie, erróneamente, a una aparente "retirada" de la fuerza en aras del "pensamiento débil". Para nada. Heidegger lleva a cabo una apuesta por la fuerza pero no por la fuerza de la argumentación, sino por el poder [ macht] del Boden que, desde el Discurso de Rectorado, se transforma en Blut und Boden [sangre y suelo o tierra) como consecuencia de una lógica existencial implacable con el otro.

A su vez, la interpretación de que la ontología de Heidegger ya no es rígida gracias a la interpretación de Vattimo carece de fundamento. La razón de esto se genera en confundir (algo que hicimos casi toda una generación) la "des-rigidización" del sujeto con lo que realmente Heidegger decía: "des-arraigo", "falta de suelo [Bodensolosigkeit) del sujeto moderno". Y tenía razón, contra los posmodernos, ya que, en efecto, el sujeto cartesiano, el sujeto lockeano, el sujeto spinozista, el sujeto kantiano y el sujeto hegeliano-marxista, son sujetos cuya subjetividad no está en su origen nacional, sino en su destino universal.

Jacques Derrida se equivoca, también, al presentar un Heidegger "deconstruccionista". La ontología de Ser y tiempo no viene a deconstruir el sujeto, el alma, el yo, la razón y la persona; sino a destruirlos. El término alemán, Destruktion, que se utiliza desde el Informe Natorp 
de 1922 no deja lugar a la menor duda: la intencionalidad de la conciencia ha sido sustituida por una conciencia, al parecer, más grande y profunda, la "intencionalidad plena" o Sorge, cuidado de la existencia o Dasein. La filosofía, la ciencia, ya no obedecen a un criterio teórico de una "teoría de la verdad" como la que se cumple en Platón, Aristóteles, san Agustín, Descartes, Leibniz, Hume, Kant o Hegel. Heidegger destruye el fundamento teórico del Círculo de Viena -Carnap. Schlick, Neurath... casualmente judíos- al proponer como "fundamento" de la "verdad" la proximidad al fundamento o suelo, la proximidad al "origen"... de Grecia= Germania.

Ahora bien, para llevar a cabo esta teoría de la verdad necesita Heidegger destruir la República democrática de Weimar. Esta, y no otra, como creyó Vattimo, es la razón del frontispicio de Ser y tiempo: "nada de cuentos" del sofista. ¿Por qué? Porque, a juicio de Heidegger, la Alemania de los años veinte estaría en la misma tesitura que la Atenas de Pericles: el sí o no a la democracia ateniense depende de una teoría de la verdad participativa, representacional, subjetiva, con derecho a voto y a veto. Pero, ay, la hermenéutica del logos que está llevando a cabo Heidegger es, nunca mejor dicho, ontológicamente anti-democrática. Nos pone en una disyunción exclusiva: o Ser $($ Dasein $=$ Volk $=$ Boden $=$ Sprach $=$ Staat $)$ o sistema político deliberativo. De ahí la tesis existencia heideggeriana sobere el mundo de la "opinión pública”, el Se o Das Man. Es inauténtico porque la libertad de expresión, la democracia, se opone frontalmente a las supestas prioridades ontológicas y políticas del origen del Ser. Todo el $\$ 77$ de Ser y tiempo está dedicado a combatir, a destruir, el mundo construido por los sofistas y Pericles, y de ahí, la lectura im-prudente que llevó a cabo del Libro vi de la Ética a Nicómaco.

Para Heidegger - y Vattimo- no hay otro mal que la globalización. Pero por "globalización" entendió Heidegger en la Carta sobre el humanismo "desarraigo" tal y como se deduce, efectivamente, de la teoría de la verdad del Círculo de Viene o de Wittgenstein o de Kant o de Nietzsche, "apátrida”, "hombre moderno" (La Gaya ciencia, §377: Wir Heimatlosen).

Por lo tanto, el error de Vattimo consiste en creer que Heidegger rescataba a las personas cuando lo que hacía en su ontología era una "autoafirmación” del Volk alemán. La comparación que (en Beuchot, 
Vattimo, Velasco, p.29 y ss.) Vattimo hizo de "Tiempos modernos" de Charles Chaplin con la crítica a la modernidad que late en Ser y tiempo es insostenible a la luz de una lectura contextualizada y más profunda. Daremos un botón de muestra sacado del propio Heidegger.

No existe más que un solo "Estado de vida" [Lebensstand]. Este es el Estado del trabajo enraizado en el fundamento portador del pueblo y libremente ordenado en la voluntad histórica del Estado, cuyo sello [Prägung] está profundamente en el movimiento nacionalsocialista del partido de los trabajadores alemanes [la traducción es nuestra] (GA 16, p. 259).

Pero Vattimo va -igracias a Dios!- mucho más allá de Heidegger; tan romo como resentido que le hizo decir al gran heideggeriano Franco Volpi: "Goodbye, Heidegger!” (Quesada, 2013). Gianni Vattimo, un filósofo no sólo elegante sino ética y políticamente comprometido con el más débil y afirma que "La versdad es la caridad" (Hermenéutica analógica y hermenéutica débil). Jamás pudo abirse Heidegger a esta perspectiva tan integradora y tan antiheideggeriana. Pero ¿̇por qué anti-heideggeraina? Porque, querido y admirado Vattimo, la caridad no sólo es una vivencia o un sentimiento, sino una acción propia, exclusivamente del ser humano que es el animal de la caridad y la generosidad, capaz de hacer abstracción del "origen" y el "destino" del amor.

\section{La Hermenéutica analógica [HA] como Teoría de la acción humana}

En nuestra opinión el hecho, decíamos en páginas anteriores, de que Beuchot Puente no utilice para nada a Heidegger cuando construye el paradigma HA le da cierta ventaja respecto de la hermenéutica del pensamiento débil que, siempre a nuestro juicio, implica, paradójicamente, una confusión del propio Heidegger.

La HA no es, como piensa su propio autor, Beuchot Puente, "un instrumento": "funciona bien como un instrumento interpretativo" (Hermenéutica analógica y hermenéutica débil, p. 20). Obviamente es un instrumento interpretativo; pero su fundamento es ontológico: implica una renovada teoría de la acción humana. Gianni Vattimo lo ha visto al transformar, muy perspicazmente, la hermenéutica analógica en "hermenéutica anagógica” (p. 21 y ss). En efecto, un mero instrumento es 
un automatismo de robot; por ejemplo la fiebre es el síntoma corporal de una infección en la garganta que el médico sabe interpetar, también la brújula es un instrumento que nos sirve para interpretar-orientarnos en el mundo y, otro ejemplo más, hay máquinas que, como Babylon, traducen automáticamente del ruso al español y viceversa. Pero en ninguno de estos ejemplos está implicado el sujeto, la persona, como tal hacer humano. El médico no es que sea imprudente cuando no toma en cuenta las pulsaciones del paciente, o ni siquiera usa el termómetro. El médico no sabe de medicina, eso es todo. Si al construir una casa no tenemos en cuenta el occidente y el oriente, la arquitectura de la casa puede verse afectada por el desconocimiento geográfico; a su vez, para poder usar-orientarnos en Babylon se necesitan conocimientos que no afectan a nuestra moralidad. Mientras que en el caso de HA hay un $a$ priori aristotélico-kantiano directamente relacionado con la persona y las otras personas: el a priori de la razón práctica.

Únicamente es esta prioridad ético-política la que puede orientarnos en el pensamiento, en la acción humana que no puede ser reducida a poíesis, "producción", como si un texto, un libro, sólo fuera un mero objeto producido como mercancía. Y sólo a lo puramente objetual o meramente objetivo se le puede aplicar el pensamiento débil así como la desconstrucción derridiana.

Nuestra tesis es que HA es una teoría de la acción humana nada posmoderna pero sí muy contemporánea. Hermenéutica anagógica, ha comentado Vattimo, es la que orienta en aquella orientación cuyo centro de gravedad está en la subjetividad como moralidad responsable. Yo no produzco la fiebre de mi cuerpo, sino el organismo que también soy. No está en el ser de la brújula imantada dejar de mirar hacia el Norte, y para el formateado de Baylon el término "vodka" es sinónimo de alcohol y ahí está la razón de ser de que ni la ginebra ni el vodka se congelen en nuestros frigoríficos. La interpretación de un texto, sin embargo, sí depende de mi como ser humano si lo que se desea, en verdad, es interpretar, entrar en comunicación con el otro.

Hay en HA un supuesto revelador que lo convierte en "acción humana": el hacernos cargo de la "pérdida" que supone toda interpretación y cualquier traducción. Interpretar un texto del siglo iv a de C., por ejemplo, la Oración fúnebre de Pericles implica un acto de condolencia, como la denotación de un "luto". Pero no porque el tema tenga que 
ver con los muertos, caídos, en una de las geurras de Atrenas contra Esparta; sino porque, y lo decía Quevedo, siempre estamos escuchanco con los ojos a los muertos. Gracias a HA se rompe el objetivismo en el que, a la postre, cayó el propio Derrida, pues su tesis central, des-construcción, es rehén del mercantilismo productivo que quiere criticar. Igual pasa con el pensamiento débil de Vattimo, rehén de la tela de araña que monta Heidegger en torno al Dasein $=$ Volk $=$ Staat, sin no fuera por el milagro subjetivo, humano, demasiado humano, de la caridad. Y hasta el propio Gadamer ha de reajustar las tesis völkisch de su maestro Heidegger para abrirse a la "prudencia" como virtud del inter-préte. Este "inter" es la subjetividad moral de la persona y el fundamento último de su soberanía individuial como ser humano autónomo. En HA la prioridad no es ontológica: lo que hay; sino lo que debe haber. Esa es la diferencia- convergencia con el pensamiento débil.

¿Identidad?, por supuesto; pero con su diferencia (p. 16). Pero ¿qué es la diferencia? A Beuchot Puente no le interesa tanto la diferencia objetiva como la subjetiva. Me explico. Como antiguo tomista pertrechado en la lógica de Bochenski sabe que la pregunta por el "ser" es ineludible; pero el paso que da en HA lo vincula ya a una determinada tradición aristótelico-kantiana en donde el ser de la lógica deja paso para que percibamos el mundo a la luz, nueva luz, de la contingencia de la que carece el mundo perfecto de la lógica y sus axiomas eternos. Ahora hay algo nuevo bajo el Sol: la interpretación, la aparición de la novedad que relanza a la propia vida abierta y plural hacia un trascendental infinito. Si un servidor, por ejemplo, se maneja mal en lógica no es por imprudente sino por falta de conocimientos lógico-matemáticos. Si en el punto x del río de la Antigua, Veracruz, se necesita de un puente peatonal y otro para vehículos pesados su construcción, su producción, implica una lógia: hacerlo, producirlo, bien. Pero si el constructor, el arquitecto, no utiliza adecuadamente y o $\mathrm{z}$ materiales, el puente se caerá con una posible pérdida de dinero y, sobre todo, vidas humanas. Luego el arquitecto era un inmoral; sin embargo, y como nos explicó Aristóteles hace ahora veinticino siglos en la Ética a Nicómaco, vi y viI, ese juicio mora/nmoral ya no depende del conocimiento teórico del que, a su vez, depende la "producción técnica" (o artística), sino de lo que como ciudadano se le supone: phrónesis. Los 
teoremas de lógicas no se resfrían; pero la gente, los mortales, sí. Esta es la poderosa razón de que el Estagirita aprecie como virtud máxima de la polis, y tanto para el dirigente como para los ciudadanos, la prudencia, virtud de orden práctico que hace posible la distinción entre un acto humano y otro que no lo puede ser como el de la construcción de un puente, cosas que también hacen los castores, las hormigas y las arañas... por naturaleza.

En Beuchot Puente brilla por su ausencia Heidegger y esto posibilita que HA se inscriba en el legado, decíamos, aristotélico-kantiano de una Escuela de Frankfurt apadrinada teórica y ético-políticamente por Max Horkheimer. ¿Quién? El -a pesar de todo- kantiano, aristotélico-kantiano Horkheimer (Materialismo, metafísica y moral).

¿Podemos deconstrir la carne? ¿Es lo mismo deconstruir las meninas de Velásquez, producción de Picasso, que deconstruir el Holocausto como hace Heidegger en la conferencia dada en Bremen en 1949 con el título "Die Gefahr" ("El peligro")?

Tan sólo la prudencia puede, decíamos, orientarnos en la interpretación: "hermenéutica anagógica". Interpetrar es salir de uno mismo. Husserl, Merlau-Ponty a la vista. Sólo por un acto reflexivo de mi conciencia puedo salir del solipsismo y volverme un ser entre los seres en donde "cabe" la prudencia. A partir de ahí el radio de acción de la prudencia puede tornarse infinito con la propia flecha del tiempo que lanza el arco de la acción humana: ¿y por qué no una hermenéutica ecológica? Pero esto es otro problema en el que no entramos.

Para la HA interpretar es ver entre las gentes. Es relativamente fácil hablar del Mitsein, del "ser-con" los amigos, familiares o los propios y auténticos. Pero ¿quién se hace cargo del ser con otros? La "analogía" (p. 16) encierra un proyecto de vida abierta, en continuo devenir, porque se renueva el texto del mundo que no sólo está escrito en caracteres matemáticos, que también es cierto; pero hay más: mis dolores de muela, mi amor y desamor, la pobreza y la generosidad, esa determinada que forma que usted tiene para vestirse, el tono de voz, la forma de amar o de expresar nuestra crueldad, la risa contagiosa, el luto humano, la sequedad de la boca del sediento en medio de un mundo de estrellas de fútbol cuyo traspaso cuesta 100 millones de euros... Hay tantísimas cosas que describir que ninguna ontología, ninguna novela, 
ninguna interpretación puede dar Fin al acto humano de la interpretación.

No, no es un mero instrumento la HA; sino una teoría del hombre, de la mujer, cuyo ser consiste en interpretar. Pero con un plus ético-político más difícil de encontrar en Nietzsche. La prioridad de la autonomía moral del sujeto es lo que nos puede orientar ante el Nihilismo del "todo vale" o "nada vale". Ninguna de estas dos tesis, ambas posmodernas, cansadas las pobres, ay, de Occidente, ninguna de estos dos conformismos sirven para orientarnos en el mundo del "entre" las personas.Cada persona vale un milagro. Es la profunda enseñanza de HA: los muertos resucitan. Interpretar es, en efecto, resucitar a los muertos con nuestra propia lengua. A diferencia del cierre ontológico que lleva a cabo Heidegger, un solipsismo peor que el de Descartes, el solipsismo del Volk alemán pero contra el resto de las interpretaciones, contra la posibilidad de que el individuo puede desencadenarse de su tribu, contra esta ontológica im-prudencia se yergue, a pesar del nihilismo flotante universitario, el acto humano del "comprender" no ya mi pueblo; sino, insisto, al otro, al que no es como yo, al que piensa de otra forma, al otro que también es idéntico a mi en relación al sufrimiento y la alegría, esas conmociones transnacionales de la risa, del luto.

Prudentemente Beuchot Puente comienza por no destruir, sino integrar; tal y como de forma sabia hace el arqueólogo con las ruinas que va encontrando al sumergirse en la historia de los que mos antecedieron. La "analogía" tiene ya su historia y no se puede partir de cero, ni de una cultura jerarquizada sobre otra. No hay propios ni impropios, no hay auténticos ni inauténticos: "todos somos herederos" (Juan Manuel Navarro Cordón). Y porque todos somos herederos de la vida y del mundo-logos, todos acusamos de recibo la "pérdida".

Beuchot Puente así lo expresó en 2006: el texto "encarna” un "hecho". Luego no es un mero objeto es, como el propio mundo, un Mundo-Logos, un mundo proferido (pp.16-17) que ahora se memoriza, se encarna en nuestro presente a través de nuestro propio cuerpo(S). Siempre en plural porque pensar, interpretar, no lo hago yo sólo sino conmigo el ancho mundo que soy y me vive entre los demás cuerpos que forman el mudo de mi propia percepción. Yo soy yo y todo lo que he leído. 
En la HA hay una metafísica crítica cuyo suelo, a diferencia de lo que hayamos en Ser y tiempo, es la conciencia: con-ciencia. Tomar conciencia, orientarnos en la interpretación. El mismo Beuchot Puente usa términos de la Dialéctica Trascendetan de la Crítica de la razón pu$r a$, así lo comprendo, cuando hace de la hermenéutica un acto humano, exclusivamente humano, mediante el que tomamos conciencia del "límite" y de la "lejanía" (p. 17). Al interpretar salgo de mi ipseidad fáctico-histórica para abrirme a otras lenguas, otras culturas, otras perspectivas, otras vidas embridadas por la misma contingencia de ser, de ser seres humanos. Identidad y milagro de la interpretación. Cada uno de nosotros es un intérprete. Pero éste, transformado en ser humano por las ideas, ya no puede ser una mera repetición del sí mismo.

¿A qué apunta la HA? Anagógicamente la HA anhela tres planos metafísicos que se dan cita, una cita infinita, el cielo puede esperar, a) la verdad; b) la libertad, y c) la felicidad (p. 17). No se trata de la verdad unívoca ni del relativismo nihilista posmoderno. Se anhela la verdad porque no se quiere acabar identificando a las víctimas con los verdugos. Se anhela la libertad que hay inscrita en la pluralidad de los cuerpos-rostros que interpretan y forman parte de la interpretación como Mundo-logos, y se anhela la felicidad porque la verdad de las "asociaciones" (p. 17) no apunta a lo meramente empírico y finito sino a lo espiritual que trasciende todo mundo circundante o inmediatez a la que se le quiere aherrojar a la persona. ¿Qué es si no asociarse sino ir más allá de uno mismo? El alma o espíritu o yo tensado por el arco que forma cada ser humana con el mundo hacia lo que está más allá del cierre ontológico de la finitud.

He aquí, pues, que el Mundo sí tiene sentido. No está huérfano nunca jamás de significado aunque este, en efecto, se nos presenta en "el horizonte de lo infinito" (Nietzsche: La gaya ciencia, §124). La HA no sueña con un horizonte cerrado de mundo y acabado. No anhela la presencia plena del ser sino que vive la contingencia a fondo en cada interpretación. No cuida - como si fuera algo únicamente suyo y en propiedad ontológica- el canon de la vida; sino la vida plural, abierta, desbordada siempre por el des-orden de metonimias y metáforas (Beuchot, Vattimo, Velasco, p. 18). No una hermenéutica modelo sino una hermenéutica que se sabe "hacia un nuevo modelo de interpretación” (subtítulo de la obra principal de Mauricio Beuchot) y, por esta 
perspectiva filosófica, una hermenéutica no para la muerte sino para la vida. Una interpretación como forma de vida que ya no anhela ni el origen (Herkunft), ni el final (Ende) del juego; sino el Juego.

\section{Referencias}

Aristóteles, 2003, Ética a Nicómaco, Alianza Editorial, Madrid.

Beuchot, M., 2005, Tratado de hermenéutica analógica. Hacia un nuevo modelo de interpretación, Facultad de Filosofía y Letras. UNAM/Editorial Ítaca, México.

Beuchot, M., G. Vattimo y A. Velasco Gómez, 2006, "Hermenéutica analógica y Hermenéutica débil", Colección Cuadernos de Jornadas, no. 14, Facultad de Filosofía y Letras. UNAM, México.

Heidegger, M., 1974, Ser y Tiempo, Fondo de Cultura Económica, México.

—, 2000,Gesamtausgabe, Vittorio Klostermann, Fránkfort del Meno.

—, 2001, Sein und Zeit, Max Niemeyer Verlag, Tubinga.

—, 2001, Carta sobre el humanismo, Alianza Editorial, Madrid.

—, 2002, Interpretaciones fenomenólogicas sobre Arsitóteles: Indicación de la situación hermenéutica [Informe Natorp], Trotta, Madrid.

—, 2003, Ser y tiempo, Trotta, Madrid.

Horkheimer, M.,1998, Materialismo, Metafísica y Moral, Tecnos, Madrid.

Kant, I., 1978, Crítica de la razón pura, Alfaguara, Madrid. 